\title{
Propuesta de intervención individual para el desarrollo del lenguaje en educación infantil
}

\section{Proposal for individual intervention for language development in early childhood education}

DOI: $10.46932 /$ sfjdv3n1-009

Received in: Dec 30st, 2021

Accepted in: Jan 1th, 2022

\author{
Maria Del Carmen Vivero Riquelme \\ Graduada en Educación Infantil \\ Universidad de Murcia \\ Calle Gabriel García Márquez 2 \\ E-mail: investigacionrgformacion@gmail.com
}

\begin{abstract}
RESUMEN
Este estudio consta de un programa de intervención para observar como evoluciona el desarrollo del lenguaje de los niños desde edades muy tempranas, para ello, debemos realizar una evaluación del sujeto estudiando su entorno social y escolar del infante, el papel de las familias. Una vez obtenida toda la información realizamos un programa de mejora adaptado a las características del niño proponiendo una serie de actividades teniendo como objetivo principal promover el desarrollo lingüístico, posteriormente obtendremos información sobre como se ha desenvuelto el menor a través de las actividades propuestas y diseñaremos una base de datos donde anotaremos todos los cambios percibidos.
\end{abstract}

Palabras clave: educación infantil, linguaje, intervención educativa.

\begin{abstract}
This study consists of an intervention program to observe how children's language development evolves from a very early age, for this, we must carry out an evaluation of the subject studying their social and school environment of the infant, the role of families. Once all the information has been obtained, we carry out an improvement program adapted to the characteristics of the child proposing a series of activities with the main objective of promoting language development, later we will obtain information about how the minor has developed through the proposed activities and we will design a database where we will record all the perceived changes.
\end{abstract}

Keywords: early childhood education, language, educative intervention.

\section{EVALUACIÓN DE UN SUJETO}

En primer lugar hemos entrevistado a los padres para poder recoger una serie de datos de la historia personal del niño, estos, más tarde, serán contrastados mediante la observación directa con el sujeto. Además, le hemos pasado un cuestionario con preguntas abiertas para recoger una información más específica. 
Elena González nació el 3 de Mayo del 2012, el embarazo tuvo lugar a la treinta y nueve semana de gestación, considerando un embarazo término que se produjo sin ningún problema.

Con respecto al desarrollo evolutivo, su desarrollo psicomotriz siguió los hitos propios de la edad cronológica, Elena empezó a dar sus primeros pasos a los nueve meses, con ayuda, y a los quince empezó a hacerlo solo.

La alimentación hasta los cinco meses fue láctea, sin mostrar ningún tipo de intolerancia alimenticia, a partir de este mes se fueron introduciendo alimentos, como papillas de frutas y verduras. Comenzando a parecerse la alimentación a la de los demás miembros de la familia, menos triturada y variada, intentando que vaya aprendiendo, poco a poco, a comer solo. También será una ayuda la aparición de los dientes posteriormente.

Las primeras palabras de Elena surgen antes de cumplir los dos años, a los veintiséis meses mantiene pequeñas conversaciones, además de los balbuceos correspondientes de todos los bebes. La aparición del lenguaje estuvo muy relacionado al entorno familiar debido a que el entorno familiar estimulo a la niña con imágenes, sonidos, libros de palabras, conversaciones...

Refiriéndonos al nivel social, podemos decir que la niña se desenvuelve con total normalidad en el ámbito familiar, mostrándose muy abierto con los demás miembros de la familia, sin mostrar vergüenza ante ningún miembro de la familia e incluso con personas desconocidas.

\subsection{DATOS FAMILIARES}

Elena es la pequeña de 3 hermanos de un matrimonio compuesto por Raquel y José. La familia está compuesta por ambos cónyuges, y tres niños. Joselito de 10 años, Laura de 8 años y Elena de 5 años. Los tres hermanos tienen muy buena relación entre ellos, aunque en ocasiones tienen peleas de hermanos, sin mayor importancia.

La niña asistió a guardería desde sus 2 años de edad, debido a que sus padres querían incorporarla al sistema educativo para poder realizar las labores que ambos deben hacer. Elena nunca ha mostrado ningún tipo de problema ni en la guardería, ni en el colegio. A día de hoy la niña es un poco revoltosa y a veces le tienen que regañar en clase.

La familia goza de un nivel educativo y económico relativamente bueno, Raquel es ama de casa y José tiene una empresa de reparación de maquinaria. La familia vive en un piso del Palmar (Murcia), y los tres hermanos van al mismo colegio ("CEIP Pedro Pintor Cano") ubicado en el mismo pueblo donde habita la familia. El colegio está ubicado cerca del domicilio familiar, y enfrente se encuentra el centro de salud. El pueblo dispone de 2 pabellones donde los niños pueden ir a piscina una vez al mes. Además de 5 colegios más en el municipio. 


\subsection{DATOS DEL MEDIO SOCIAL}

La niña dispone de un entorno social que le proporciona buenos estímulos, que fomentan su aprendizaje como por ejemplo la familia, la cual se preocupa mucho por el aprendizaje que deben de llevar sus hijos. Los niños se relacionan con amigos del parque por las tardes, algunos son mayores que Elena, lo cual le puede ayudar en su aprendizaje. Además de ir al parque los niños van a piscina.

Los medios de comunicación también son una parte muy importante en la futura educación de los niños, por eso los padres están muy pendientes de los canales que sus tres hijos ven en la televisión.

\subsection{DATOS DEL MEDIO ESCOLAR}

Actualmente Elena cursa el último curso de su etapa escolar en un colegio de titularidad pública y bilingüe, ubicado en la calle Pintor Pedro Cano de El Palmar (Murcia). Este centro cuenta con tres líneas en la etapa de Educación Infantil, habiendo entre 20 -22 alumnos por aula, agrupados por mesas triangulares de colores, estas son consideradas para Elena los equipos. En relación al sistema de enseñanza hemos investigado en la página web del CEIP y hemos obtenido información sobre el colegio, posteriormente la hemos contrastado con la familia, donde hemos preguntado personalmente a Elena que nos relata la rutina que sigue todos los días en clases, destaca que son fundamentalmente participativas (asambleas, juegos, actividades en grupo e individuales). Las aulas del centro cuentan con pizarra digital y además en el rincón de las tecnologías disponen de Tablet.

El colegio dispone de unas instalaciones muy nuevas, debido a que está poco tiempo construido. El colegio dispone de las aulas correspondientes para acoger a los alumnos, además de varios patios, y pistas para jugar los niños. Otro de los recursos que tiene este colegio es que presenta comedor y actividades extraescolares.

El comportamiento de Elena al llegar a la escuela, es un comportamiento social relativamente bueno, debido a que suele saludar a la maestra y a los compañeros de clase, deja la mochila en el perchero y se va a la asamblea, donde se desarrolla : saludos, tiempo... Además, se recuerdan las normas de funcionamiento del aula. Elena se comporta de forma correcta ante las normas e incluso es capaz de reconocer cuando se incumple alguna. Nuestra niña prefiere las actividades individuales de carácter manipulativo ya que la niña muestra una buena actitud hacia los premios, e intenta en todo momento ser recompensada con una cara sonriente cuando las acaba. Elena muchas veces no es recompensada por su dificultad para no hablar cuando la profesora está explicando, o algún compañero está hablando.

Respecto a los tipos de ayuda que necesita para mejorar:

- Aprender cuando no debe hablar en aula, como cuando esté hablando la profesora o compañeros 


\title{
2 INFORME DE RESULTADOS DE LA EVALUACIÓN.
}

Una vez que hemos llevado a cabo el primer acercamiento con la familia y la pequeña, por medio de entrevistas y conversaciones con la niña le hemos pasado una hoja de registro con ítems de distintos intervalos de edad.

Iniciaremos con el intervalo anterior a su edad, de 48 a 60 meses comprobando que supera todos los ítems sin ninguna dificultad.

Por tanto nos encontramos con una niña de 5 años de edad, a la que le aplicamos los ítems correspondientes a su edad, 60-72 meses, tomamos como referencia los tres primeros ítems:

1. Expresa opiniones.

2. Desarrollar un vocabulario más completo.

3. La mayoría de los fonemas son pronunciados adecuadamente.

\begin{abstract}
Destacamos que Elena es una niña muy habladora, a la que le cuesta respetar los turnos a la hora de hablar los demás compañeros, se muestra alterada al ver que no puede expresarse cuando ella quiere y no tiene ningún reparo a la hora de intervenir en clase y expresar como se siente, siempre quiere ser el centro de atención. Elena mantiene un tono de voz adecuado, aunque algunas veces altera su tono de voz cuando no le dejan expresar su opinión. El último ítems es que pronuncia correctamente todos los fonemas y a pesar de vivir en Murcia, no se come ninguna -s, y apenas tiene acento murciano.

Debido a que cumple con éxito todos los ítems adecuados a su edad, continuaremos con los ítems posteriores de la misma tabla, para comprobar si los realiza correctamente.
\end{abstract}

1. Lenguaje expresivo y tolerante.

2. Capacidad de describir y verbalizar.

3. Capacidad de comprender y ejecutar ciertas órdenes.

No muestra ningún problema a la hora de expresar lo que piensa con sus compañeros, con los adultos, y con niños mayores a su edad, por tanto podemos decir que no es para nada una niña tímida y siempre que lo necesita pide ayuda a los adultos.

Utiliza sobre todo los verbos en primera persona y siempre hace uso de los verbos de la primera conjugación.

El inconveniente viene cuando a la niña le imponemos una orden, la madre nos cuenta que no le presta atención a las órdenes ni tanto de ella ni de la profesora que se muestra rebelde.

\section{PROGRAMA DE MEJORA EN EL ÁREA CORRESPONDIENTE:}

\subsection{OBJETIVO GENERAL.}

\subsection{OBJETIVOS CONCRETOS.}

$\checkmark$ Ítem: Expresar opiniones.

\section{$\underline{\text { Objetivo general }}$}

1. Potenciar el lenguaje a la hora de relacionarse con los demás.

\section{Objetivos concretos}


1. Utilizar el lenguaje con flexibilidad y eficacia.

2. Exponer ideas y opiniones con claridad y relacionar las intervenciones con las de los otros oyentes.

$\checkmark$ Ítem: Desarrollar un vocabulario más completo.

\section{$\checkmark$ Objetivo general}

1. Incrementar las habilidades de comunicación, expresión y vocabulario.

$\underline{\text { Objetivos específicos }}$

1. Fomentar el uso de familias de palabras, semejanzas/diferencias, contrarios.

2. Aumentar el vocabulario a través de la lectura de imágenes

$\checkmark$ Ítem: 3. La mayoría de los fonemas son pronunciados adecuadamente.

\section{Objetivo general}

1. Dominar el lenguaje castellano

\section{Objetivos específicos}

1. Conocer las consonantes y las vocales

2. Realizar ejercicios para identificar fonemas

\subsection{ACTIVIDADES}

Para conseguir estos objetivos llevaremos a cabo una serie de actividades. El objetivo principal es promover el desarrollo lingüístico de Elena obteniendo unas competencias en el entorno escolar, en el entorno familiar y social más cercano (la calle, la escuela, la familia, el grupo de iguales, en su tiempo libre,...).

A continuación hemos programado una serie de actividades, distribuidas en los cinco días de la semana, durante un mes. Estas quedan expuestas en las tablas que se muestran a continuación: Ítems:

\section{Expresar opiniones}

2. Desarrollar un vocabulario más completo.

3. La mayoría de los fonemas son pronunciados adecuadamente. FICHA PROGRAMACIÓN ACTIVIDADES EDUCATIVAS ACTIVIDAD N: 1 TÍTULO: Juego de los cuentos

DURACIÓN: Todos los días lectivos por la mañana al entrar al aula.

FECHA: La primera semana del mes de Octubre. 
DESARROLLO: La profesora reparte unos cuentos con palabras nuevas que se repiten mucho y los niños tienen que explicar esas palabras que ya han visto en clase y han trabajado. Así los niños aprenden nuevo vocabulario y nuevas palabras.

PERSONAS IMPLICADAS: la profesora, Elena y los demás compañeros

LUGAR: el aula

FICHA PROGRAMACIÓN ACTIVIDADES EDUCATIVAS. ACTIVIDAD N: 2.

TÍTULO: Juego de palabras

DURACIÓN: Los viernes antes de finalizar las clases, durante 15 minutos.

FECHA: La segunda semana de Octubre.

DESARROLLO: La profesora mostrara a sus alumnos una serie de viñetas y está explicara el significado de cada imagen, a su vez en la pizarra anotara una serie palabras, los niños mediante el significado que le ha proporcionado la profesora deberán de adivinar el nombre de la imagen.

PERSONAS IMPLICADAS: la profesora, Elena y los demás compañeros

LUGAR: el aula

\subsection{LA MAYORÍA DE LOS FONEMAS SON PRONUNCIADOS ADECUADAMENTE.}

FICHA PROGRAMACIÓN ACTIVIDADES EDUCATIVAS. ACTIVIDAD N: 3

TÍTULO: "Aprender los fonemas"

DURACIÓN: Todos los días de la semana

FECHA: Desde el inicio del curso

DESARROLLO:

Aprender a articular por ejemplo el fonema /R/ propagar el fonema una vez aprendido al lenguaje espontáneo. Los niños jugarán a través de una serie de ejercicios de onomatopeyas, discriminación auditiva, repetición de palabras, rimas, adivinanzas, integración fonética y discriminación de pares fonológicos.

PERSONAS IMPLICADAS: La profesora y todos los niños

LUGAR: en el aula

FICHA PROGRAMACIÓN DE ACTIVIDADES EDUCATIVAS. ACTIVIDAD N: 4

TÍTULO: Juego de clasificación

DURACIÓN: Tres veces por semana, concretamente los lunes, miércoles y viernes

FECHA: La cuarta semana del mes de Octubre 
DESARROLLO: La profesora repartirá a los alumnos una serie de fichas dónde irán incorporadas varias imágenes. Los niños deberán encontrar y explicar por qué es el contrario de la imagen correspondiente.

PERSONAS IMPLICADAS: Todos los niños y la profesora

LUGAR: El aula

1. Expresar opiniones

\section{FICHA PROGRAMACIÓN DE ACTIVIDADES EDUCATIVAS. ACTIVIDAD N: 5}

TÍTULO: ¿Y tú qué opinas?

DURACIÓN: Una semana, concretamente los jueves con una sesión de 20 minutos.

FECHA: La primera, segunda y tercera semana del mes de Octubre

DESARROLLO: La profesora mostrará a los niños unas imágenes de varios objetos, cada niño tendrá que elegir una imagen, la que más le guste e interese y la que más le llame la atención. Después, una vez elegidas las imágenes, deberán escribir en una hoja para que sirve cada objeto elegido, si tienen alguno y si les gusta o no. A continuación, deberán explicarlo a los demás compañeros para que todos opinen también sobre el objeto de cada uno.

PERSONAS IMPLICADAS: La profesora

LUGAR: el aula

FICHA PROGRAMACIÓN DE ACTIVIDADES EDUCATIVAS. ACTIVIDAD Nº: 6

TÍTULO: La flor de la opinión

DURACIÓN: Los jueves y viernes

FECHA: La segunda y tercera semana del mes de Octubre

DESARROLLO: Los niños dispondrán de una flor la cual será pasada en la asamblea, tendrán que expresar como se sienten en ese momento, y relacionarlo con una imagen. En el aula habrá imágenes de los diferentes emoticonos para que los niños las relacionen con sus estados de ánimo

PERSONAS IMPLICADAS: la profesora y los alumnos

LUGAR: el aula

\subsection{EVALUACIÓN DE PROGRESOS. (REGISTROS, ¿CÓMO SABREMOS QUE SE PUEDEN CONSEGUIR LOS OBJETIVOS?}

Una vez que conocemos cuales son los puntos débiles de Elena, dígase a la hora de respetar el turno de palabra en clase, no ejecutar las órdenes que se le dicen, y por mostrar rebeldía, hemos procedido a 
diseñar una serie de actividades que promueven el desarrollo lingüístico del menor en estos ámbitos, paliando esos puntos débiles que presenta.

Para llevar a cabo esta evaluación, en primer lugar hemos llevado a cabo una evaluación inicial con el menor, empleando ambas metodologías, es decir, en el caso de la cualitativa, una entrevista y un cuestionario familiar, y en el caso de la cuantitativa hemos instaurado hojas de registro sobre los ítems citados en los apartados anteriores.

Elena durante un mes ha desarrollado las actividades planteadas y como es debido, hemos ido anotando los resultados de las mismas día a día en una hoja de seguimiento en la que como hemos podido evidenciar y así lo esperábamos, conforme se iba aproximando el final del plazo propuesto, Elena ha conseguido realizar con éxito, durante cuatro días consecutivos las conductas evaluadas de forma acorde con su edad de tres años.

Para rematar con el programa de intervención elaborado a Elena, provenimos a hacer una evaluación posterior para demostrar si ha absorbido estos comportamientos de forma significativa. Tras haber pasado un mes de nuestra intervención, hemos vuelto a realizar las mismas actividades planteadas anteriormente, y comprobamos que Elena tiene asentadas estas conductas, por lo que podemos decir para concluir que nuestra intervención ha sido más satisfactoria de lo que nos esperábamos, ya que hemos conseguido los objetivos planteados a pesar de haber tenido unos inicios difíciles.

\begin{tabular}{|c|c|c|c|c|}
\hline \multicolumn{5}{|c|}{$1^{\circ}$ SEMANA DE NOVIEMBRE } \\
\hline LUNES & MARTES & MIÉRCOLES & JUEVES & VIERNES \\
\hline $\begin{array}{ll}\text { JUEGO } & \text { DE } \\
\text { PALABRAS } & \end{array}$ & $\begin{array}{l}\text { FLOR DE LA } \\
\text { OPINIÓN }\end{array}$ & $\begin{array}{l}\text { APRENDER LOS } \\
\text { FONEMAS }\end{array}$ & $\begin{array}{l}\text { ¿Y TÚ QUÉ } \\
\text { OPINAS? }\end{array}$ & $\begin{array}{ll}\text { JUEGO } & \text { DE } \\
\text { PALABRAS } & \end{array}$ \\
\hline $\begin{array}{l}\text { ¿Y TÚ QUÉ } \\
\text { OPINAS? }\end{array}$ & $\begin{array}{l}\text { JUEGO DE } \\
\text { LOS } \\
\text { CUENTOS }\end{array}$ & $\begin{array}{l}\text { FLOR DE LA } \\
\text { OPINIÓN }\end{array}$ & $\begin{array}{l}\text { JUEGO DE } \\
\text { LOS } \\
\text { CUENTOS }\end{array}$ & $\begin{array}{l}\text { APRENDER LOS } \\
\text { FONEMAS }\end{array}$ \\
\hline $\begin{array}{l}\text { APRENDER LOS } \\
\text { FONEMAS }\end{array}$ & $\begin{array}{l}\text { ¿Y TUU QUÉ } \\
\text { OPINAS? }\end{array}$ & $\begin{array}{l}\text { JUEGO DE } \\
\text { PALABRAS }\end{array}$ & $\begin{array}{l}\text { FLOR DE LA } \\
\text { OPINIÓN }\end{array}$ & $\begin{array}{l}\text { ¿Y TÚ QUE } \\
\text { OPINAS? }\end{array}$ \\
\hline
\end{tabular}

Hoja de registro mes de Noviembre: Evolución

*Todas las actividades anteriormente indicadas se han puesto en práctica reiteradamente, y en esta tabla quedan manifestadas aquellas que si se han logrado de forma grata.

El programa que hemos seleccionado se centra en el desarrollo lingüístico. El propósito que pretendemos alcanzar con este es el cumplimiento de los objetivos ya planteados anteriormente; potenciar el lenguaje a la hora de relacionarse con los demás, conocer la frecuencia temporal en el espacio del tiempo y dominar el lenguaje castellano. 
Para poder alcanzarlos de manera satisfactoria, en nuestra intervención hemos seguido los siguientes procedimientos:

\subsection{EVALUACIÓN DEL SUJETO}

Para comenzar hemos entrevistado a los padres para poder almacenar una serie de datos de la historia particular del niño, para ello, les pasamos un cuestionario con una serie de preguntas de carácter abierto (periodo de gestación, posibles complicaciones en el embarazo, desarrollo psicomotriz, inicio del lenguaje, desarrollo social, entre otras). Las respuestas fueron habladas con la familia en una entrevista de no estructurada, finalizándola con un estudio del centro escolar, contexto socioeconómico y cultural, con el objetivo de contrastar la información con el menor. A través de la observación inmediata hemos podido comprobar cuáles son los problemas a tratar. (expresar opiniones, desarrollar un vocabulario más completo y la mayoría de los fonemas son pronunciados correctamente).

\subsection{DESARROLLO Y SEGUIMIENTO}

Para la puesta en marcha, desde un punto de vista práctico, de este proyecto de desarrollo lingüístico, se debe llevar a cabo una secuenciación lo más exhaustiva posible desde el punto de vista metodológico. Para el desarrollo de este proyecto se han ido recorriendo las siguientes fases:

-Planificación: es preciso concretar los objetivos generales y concretos que se van a obtener con este programa.

-Metodología: es la elección de los métodos apropiados para la obtención de los objetivos, sin perder de vista a quién va dirigido.

-Temporalización: guía que concretiza los períodos de aplicación de las actividades.

-Actividades: ejemplo para el inicio real de este programa

-Recursos: materiales espaciales y humanos que se van a requerir para desenvolver las actividades establecidas anteriormente.

-Seguimiento de cada sesión-actividad: con una hoja de registro de la evolución ejecutaremos una evaluación continua con la cual, mediante la observación directa, demostraremos los avances y la obtención de dichos objetivos.

\subsection{EVALUACIÓN}

Realizaremos una evaluación final (evaluación de mejoras, al mes de haber completado todas las actividades, específicamente en el mes de noviembre ya que dichas actividades se han elaborado en el mes de octubre). En ese momento es cuando repetiremos las actividades y comprobaremos si se han 
obtenido los logros esperados a través de las actividades Aquí es donde repetimos las actividades y comprobamos si se han obtenido los logros esperados de nuestros objetivos.

\section{RESULTADOS PREVISTOS}

Una vez que hemos realizado el programa de intervención con Elena, el cual consistía en la realización de actividades para mejorar algunos ítems relacionados con el desarrollo del lenguaje. Las principales tres conductas en las que nos hemos fijado han sido:

1. Desarrollar un vocabulario más completo.

2. Expresiones opiniones

3. La mayoría de los fonemas son pronunciados correctamente.

La realización de actividades se ha llevado a cabo de forma progresiva, con el fin de que Elena pueda llegar a mejorar las carencias que tiene, como por ejemplo cuando quiere expresar algo y no es su turno. Por ello hemos realizado este programa.

Para que se consiga con éxito este programa sería recomendable que realizáramos una generalización, con esto conseguiremos que las actividades que aprenden en el colegio se continúen en otros ámbitos, por ejemplo en casa.

Al terminar este programa de Intervención, esperábamos que Elena fuera capaz de Expresar sus propias opiniones, y de tener paciencia hasta que los otros compañeros expresen sus opiniones; Elena a demás ha mejorado su pronunciación en la mayoría de fonemas correctamente. Por último a través de este programa hemos conseguido que Elena amplié su vocabulario a través de los ejercicios con los contrarios.

Al terminar el mes previsto para realizar las actividades podremos observar si Elena ha mostrado cambios favorables. Podemos ver como Elena ahora puede expresar de forma autónoma sus sentimientos, y pronunciar todos los fonemas sin dificultad. Por ello podemos decir que hemos realizado nuestra intervención de forma autónoma.

Al finalizar este programa habrá que llevar a cabo un seguimiento, para comprobar si estos cambios que hemos querido introducir se han llevado a cabo satisfactoriamente. Podremos volver a realizar las actividades cada 3 meses, para ver si se ha aprendido de forma duradera el cambio.

\section{CONCLUSIONES DEL TRABAJO.}

- La escolarización en los primeros años de vida, desde los 0 hasta los 6 años es de vital importancia, ya que es cuando los niños deben de recibir una adecuada estimulación para favorecer el desarrollo de todas las áreas, a nivel motriz, social, cognitivo, lenguaje, entre otras. 
-La familia es el pilar básico, ya que es el entorno más próximo del menor, y es la pieza que repercute directamente en que el desarrollo lingüístico y evolutivo del niño sea positivo o negativo. La participación activa de esta junto con la escuela, es esencial para que exista una continuidad entre lo aprendido en el aula y lo que se adquiero en el entorno más inmediato, en este caso en concreto, estaríamos hablando del hogar donde se encuentra el menor, de esta manera será capaz de trasladar las conductas aprendidas a los distintos ambientes en los que se desenvuelve.

El papel de las maestras de Educación Infantil, es fundamental, ya que los niños a estas edades pasan la mayor parte del tiempo en las escuelas, su papel no solo se centra en la enseñanza de contenidos y evaluar resultados, deben ser conscientes de que son un modelo de referencia para los alumnos y por ello deben ser agentes activos en el

El lenguaje es un sistema de comunicación a la vez que un instrumento fundamental en el desarrollo del pensamiento, la estructuración de la personalidad y el carácter social del niño.

$\mathrm{Su}$ adquisición se produce gracias a un proceso de interacción con las personas del entorno y se asienta sobre las bases fisiológicas y anatómicas, siguiendo un proceso de desarrollo en el que intervienen aspectos cognitivos, afectivos y lingüísticos.

Es importante definir bien la intervención y estructurar las actividades en base a unos objetivos planteados previamente, ser flexibles y adaptarlas al ritmo del menor; además de contar con los recursos y lugares apropiados para llevar a cabo una intervención eficaz.

Además, el carácter preventivo del proceso educativo tiene un papel fundamental en la etapa de Educación Infantil, su escolarización contribuye a potenciar al máximo sus habilidades y capacidades. Las actividades propuestas se desarrollaran gracias a la colaboración de las familias y la escuela. Serán desarrolladas en los distintos ámbitos y contextos en los que se desenvuelve el niño. La familia ha de colaborar en toda la intervención. Las competencias adquiridas gracias a las actividades durante la etapa de la primera infancia, permiten un mayor conocimiento del lenguaje. Laa actividades son estructuradas según los objetivos que han sido planteados previamente. Han de adaptarse a los distintos niños que pueden encontrarse en el aula, por tanto han de ser flexibles.

\section{OPINION, COMENTERIOS Y CRÍTICAS}

Para comenzar nos gustaría destacar las oportunidades que nos ofrecen los programas de intervención. Con ellos se pueden alcanzar importantes logros con los menores, siempre y cuando se adapten a las necesidades específicas de los niños. En ocasiones estos programas pueden ser demasiado inflexibles y riguroso, para ello es conveniente que la intervención se desarrolle en el entorno natural y más cercano al menor, para que con la ductilidad que nos ofrece el programa, se mejore el aprendizaje de 
las conductas que deseamos adquirir y a la misma vez la intentar que el niño se exprese de la forma posible con sus iguales.

Es muy importante el papel de la familia, ya que los niños imitan todo lo que hacen sus padres. El desarrollo del lenguaje comienza nada más nacer cuando ve nuestra forma de comunicamos y nos escucha hablar. Cabe destacar el papel tan relevante del entorno más cercano del niño, el cual tiene que recibir una gran estimulación por parte de la familia, ya que será el detonante que indique la aparición y el ritmo del lenguaje.

Señalar que los programas de intervención deben ser flexibles, considerando el desarrollo evolutivo del menor en todos sus ámbitos, sobre todo en aquellos en los que tiene mayor problema, adaptando el programa al niño. 


\section{REFERENCES}

Anon, (2017). [online] Available at: http://www.um.es/tonosdigital/znum3/pdfs/peribiblion.pdf [Accessed 26 Apr. 2017].

Anon, (2017). [online] Available at: https://www.boe.es/buscar/pdf/2007/BOE-A-2007-185consolidado.pdf [Accessed 26 Apr. 2017].

Dle.rae.es. (2017). Citar un sitio web - Cite This For Me. [online] Available at: http://dle.rae.es/?id=N7BnIFO [Accessed 26 Apr. 2017].

Anon, (2017). [online] Available at:

http://s3.amazonaws.com/academia.edu.documents/35087318/2565Herrerav2-

Maq.pdf?AWSAccessKeyId=AKIAIWOWYYGZ2Y53UL3A\&Expires=1493199184\&Signature=Txf0

DA3HsLGbAT5Gwrh9YmZK7V0\%3D\&response-content-

disposition=inline\%3B\%20filename\%3D2565Herrerav2-Maq.pdf [Accessed 26 Apr. 2017].

Anon, (2017). [online] Available at: http://s3.amazonaws.com/academia.edu.documents/40957777/lenguaje_1.pdf?AWSAccessKeyId=AKI AIWOWYYGZ2Y53UL3A\&Expires $=1493199330 \&$ Signature $=$ VHx5Vk6hRW8mh5cH4Xpv5X3Ue9Q $\% 3 \mathrm{D} \&$ response-contentdisposition=inline\%3B\%20filename\%3DLenguaje_1.pdf [Accessed 26 Apr. 2017].

Anon, (2017). [online] Available at: http://s3.amazonaws.com/academia.edu.documents/4934901/salsa_peralta._INTERCONTINENTAL_2 001.pdf?AWSAccessKeyId=AKIAIWOWYYGZ2Y53UL3A\&Expires=1493199414\&Signature=VW\% 2BoSmdWwadTEZWiDD3dXw11m5U\%3D\&response-content-

disposition=inline\%3B\%20filename\%3DLa_lectura_de_material_ilustrado_una_est.pdf [Accessed 26 Apr. 2017].

Anon, (2017). [online] Available at: https://www.unioviedo.es/reunido/index.php/PST/article/view/8565 [Accessed 26 Apr. 2017].

Anon, (2017). [online] Available at: http://www.medigraphic.com/pdfs/fisica/mf-2002/mf02-2_4j.pdf [Accessed 26 Apr. 2017].

Ternera, L. (2017). Características Del Desarrollo Cognitivo Y Del Lenguaje En Niños De Edad Preescolar. [online] Publicaciones.unisimonbolivar.edu.co. Available at: http://publicaciones.unisimonbolivar.edu.co/rdigital/ojs/index.php/psicogente/article/view/1064 [Accessed 26 Apr. 2017]. 